\title{
Association between Healthy Lifestyle and Management of Hypertension; A Descriptive Study undertaking Sudanese Adults
}

\author{
Mutaz Ombada ${ }^{1} \&$ Mulham Ombada ${ }^{2}$ \\ ${ }^{1}$ University of Maryland Hospital, USA \\ ${ }^{2}$ King AbdulAziz University Hospital, Jeddah, Saudi Arabia \\ Correspondence: Mutaz Ombada, Nephrology fellow, University of Maryland Hospital, P.O Box 810 Mocking \\ Bird Lane apt 201 Towson, MD 21286, USA. E-mail: Mutazshurhabeel@yahoo.com
}

Received: August 29, 2019 Accepted: November 30, 2019 Online Published: December 29, 2019

doi:10.5539/gjhs.v12n1p106

URL: https://doi.org/10.5539/gjhs.v12n1p106

\begin{abstract}
Background: Hypertension (HTN) is recognized as a global healthcare challenge. It is considered as the leading mortality inducing factor for coronary heart disease, stroke, congestive heart failure, renal diseases, and retinopathy. Objective: The study aims to assess the hypertension prevalence among adults in Khartoum, Sudan. It also examined the potential risk factors that are associated with hypertension. Methods: The study employed a cross-sectional research design using a quantitative approach. A questionnaire-based survey was conducted among 138 adults aged 16-75 years, from March-April 2015, in the Riyadh district of Khartoum, Sudan. Using simple random sampling, the study recruited the participants from ward number 5 of Riyadh municipality. Data were collected related to the socio-demographic factors and hypertension risk factors. Results: The findings showed a prevalence of 28 percent, whereas the majority of hypertension cases were reported for the age group from 45-60 years group (13.7\%). The findings revealed a substantial impact of age, stress, social status, and diabetes on hypertension with a p-value of $0.001,0.010,0.001$, and 0.50 , respectively. Conclusions: It concludes that more research needs to be conducted for the analysis of the factors which can assist the detection of hypertension. It also stresses towards instigation of the awareness programs with effective preventive interventions.
\end{abstract}

Keywords: descriptive study, healthy lifestyle, management of hypertension, Sudanese adults

\section{Introduction}

Hypertension has been characterized as the burden of all diseases and served as a treatable factor globally. It is an insidious disease that is responsible for damaging many internal organs to a greater extent. Kidney failure, brain damage is some of the severe effects of hypertension on the human body (Najimi et al., 2016). Other than this, the problem is significant in predicting higher deaths due to cardiovascular disorder and promotes diabetes, smoking, mortality, and obesity. The problems provide a greater amount of financial burden to the loss of human lives and the cost of medical facilities (Aldiab et al., 2018). In global perspectives, hypertension is regarded as one of the leading causes of mortality and morbidity. High Blood Pressure in different patients leads to various health complications, such as; coronary artery disease, stroke, atherosclerosis, and other related to the heart. According to the World Health Organization (WHO), in every ten adults, 1 of them usually suffers through diabetes. While, for Saudi Arabia, 1 in every four adults is diabetic due to hypertension (Alharbi et al., 2017; De Boer et al., 2017).

Rapid growth in environmental, economic, and lifestyle has resulted in the prevalence of prehypertension and hypertension significantly. The expansion and acceleration in the process of aging due to altered dietary routines have increased the ratio of this problem in multiple regions. The problem is not only restricted to a specific area or country but has become a global issue (Osman, 2019). 47\% of heart diseases, 54\% of stroke, and 706 million premature deaths are caused by hypertension alone around the world (Aldiab et al., 2018). Saudi Project for Assessment of Coronary Events (SPACE) provided health report in this regard, where 32\% of people suffer though ischemic heart problems, 56\% of people have diabetes, $39 \%$ of people are habitual of smoking, and around $31 \%$ of people are undergoing through a problem of hyperlipidemia followed by hypertension. Noncommunicable disease (NCD) of WHO provided a report that in Saudi Arabia, 42\% of deaths are recorded, which are caused by Cardiovascular Disorder (Saeedi, 2018). Such as Saeed \& Al-Hamdan (2018) conducted a 
study regarding the prevalence of hypertension in adult males. The study highlighted that obesity and overweights are dominant risk factors associated with hypertension. Furthermore, people under the given age group (35-44) usually have low levels of education and information regarding the issue. According to Saeed (2017) majority of people among them belong to lower working class. 37.3\% having the least exposure to necessary health measures. Moreover, the problem of SDH was majorly linked with the growing age, low education levels, environmental issues, and the use of tobacco. While, people intaking balanced diet has significantly lower or no possibilities of SDH. Hosseinpanah et al. (2015) supported the idea by providing another report in 2014 related to obesity. According to this, 600 million were already suffering through the problem of obesity; however the estimated value is predicted to increase up to 1.12 million till 2030. Certainly, the problem has provided greater challenges to the health management agencies.

Major causes of hypertension are due to the systolic and diastolic forms of blood pressure. A report was presented by Joint National Committee on different issues, including; Detection, Prevention, Evaluation, and Treatment of HBP in the year (2003). The major interest of the report was provided to people avoiding the consumption of antihypertensive medicines that have SBP up to 120, while the diastolic blood pressure was between $139 \mathrm{mmHg}$ (Booth III et al., 2017). The illustrations provided that the disease serves as a silent threat to the lives of people, and is rarely guided through any visible symptoms. The problem is, however, discovered during treatments related to other problems or through healthcare screening. World Hypertension League (WHL) provided similar information that $50 \%$ of people undergoing hypertension are usually ignorant or unaware of their conditions (Masoodi, 2016).

Continuing this, treatments are only received by people who are either consuming antihypertension medicines or going through systolic blood pressure. However, $140 \mathrm{mmHg}$ of systolic blood pressure indicates controlled hypertension. Contrary to this, SBP of $110 \mathrm{mmHg}$ approximately is considered in relation to other problems, such as; chronic kidney diseases, heart, and other cerebrovascular diseases. Obesity is also characterized as another risk factor giving rise to hypertension and an increase in SBP. In such cases, the burden of SBP with $110 \mathrm{~mm} \mathrm{Hg}$ at the time remains high regardless of antihypertensive medications (Forouzanfar et al., 2017). To avoid the probabilities of diseases causing severe health risks, it is important to take necessary measures regarding medication and control of hypertension. Many countries are now working substantially to promote awareness regarding, treatment, control and prevention of hypertension. A significant increase in the number of hypertensive populations was recorded between 2000 to 2010, reaching to 1.0 billion of such population. Also, major probabilities of the given problem were recorded in low and middle incoming countries that are already undergoing through other diseases (Mills et al., 2016).

Suliman (2011) in his paper proposed that, since the problem is associated to major risk factors poor control over the disease may result in damaging various internal organs. In under developing countries like Sudan, rate of hypertension is maximum and the problem is regarded as the most common cause of heart disease. The problem however, increasingly contributes in cardiovascular diseases specifically within the given region. Alkahtani \& Al-Hariri (2016) stated that the economic boom in Saudi Arabia and changes in globalization has resulted in provision of poor diet habits and low physical activities, exposing majority of the population towards poor health risks. Notable is the fact that the problem commonly resides in people working in low labor markets. While, a significant coverage is given to the problem by private companies working to prevent their workers from the given problem.

Saad Salman (2016) studied causes of Obesity in both men and women. While characterizing their association in two genders, the study proposed that the problem in men is the substantial root cause of hypertension. For women, the problem is concerned with chronic diseases, marital status along with hypertension. Age and family history of the relevant people is another important factor considerable in this regard (Van Gaal, 2006). Several risk factors important in the provision of hypertension are still not addressed completely. A significant amount of data is required to study the given issue in other regions. The number of patients related to the given problem are expected to increase in the coming years (Wagialla \& Elnimeiri et al., 2016).

Gutierrez, Alloubani, and Alzaatreh (2018) provided important information regarding risk factors of coronary heart disease among 159 male university students. $28.9 \%$ of students were inactive in performing healthy physical activities, while $37.7 \%$ of students spent maximum time in other unhealthy activities, such as; use of computer and watching TV for hours. Almost 19\% students were habitual of smoking, other $24.5 \%$ of students were overweight, and remaining $11.9 \%$ of them were going through severe obesity. Baig, et al., (2015) studied similar idea related to the perceptions of young people regarding availability of knowledge and understanding of this disease. Most of the young population were unaware of the provided idea, but showed a positive attitude in 
acquiring relevant knowledge. Furthermore, most youngsters were optimistic towards the idea of maintaining their physical fitness. However, majority of them agreed that greater amount of knowledge regarding health concerns was acquired through electronic media.

Saeed (2016) studied Isolated Diastolic Hypertension in various adults, residing in Saudi Arabia. Risk factors such as; obesity, smoking, stress was provided major concern. Majority of the patients undergoing through the problem were unaware of their conditions. Also, treatments provided to control the problem were also unsuccessful. However, they were suggested to alter their lifestyle including low consumption of salt, regular exercises and balanced to control weight. Veiga Jardim et al. (2015) provided a follow up for 20 years in the understanding of the cardio vascular history among various individuals. The results proposed in the first phase indicated that people with significant understanding of hypertension usually are not associated with the problem. However, in the second phase people receiving treatments regarding health problems were said to have hypertension.

Mozaffarian et al. (2015) provided a statistical ratio based on gathered data in the year 2009-2012. Findings of the study illustrated that $32.6 \%$ adults aged above 20 have hypertension. The given ratio indicated the problem in almost 80.0 million of US residents. However, risk factors among these individuals were Obesity and overweight. Furthermore, among different patients suffering from Acute Strokes usually have higher risk factors of hypertension. The survey was conducted in different hospitals of Khartoum. Inadequate blood pressure was the major problem that was controlled through health care treatments. It further suggested that Sudan stands among one of those countries having significant risk factors associated to hypertension. It is important to control the problem through effective treatments, while, information dissemination may work as an effective source to prevent from the disease in future (Sokrab, Sid-Ahmed, \& Idris 2002).

Prevalence of hypertension can create greater economic burden, due to the increase rate of mortality. Health condition requiring primary care however has no little symptoms of Hypertension, in such conditions it is probable to control the problem through effective treatment. However, problems of high blood pressure are observed in people due to the prevalence masked untreated hypertension (Naser et al., 2016). Patients beliefs regarding their treatments of hypertension are also considered as an important factor in providing positive results. Najimi et al. (2016) argued that results regarding hypertension treatments are highly disappointing in various cases. Effective results of the provided treatment can be achieved through proper counselling of hypertension patients, this can contribute in balancing their beliefs and may provide positive outcomes.

Hypertension, in the present age has become a growing problem of the community, contributing in the development and growth of various health problems and cardio vascular diseases. The extent of its increasing growth can be understood, as around billion people are now dealing with the problem globally. Total $13.5 \%$ deaths are recorded each year around the world (Bui Van et al., 2018). Several risk factors, such as; the growing age, lack of fitness, frequent usage of alcohol and tobacco, innutritious diet along with maximum salt consumption contribute in the rapid development of the problem.

As stated by the World Health Organization (2015) that to control such diseases, it is important to provide a significant value to non-communicable diseases (hypertension) to prevent and control the growing risk factors leading towards death. The capacity of concerned management to target the given issue must be fully integrated in providing health care information. Also, it is important to raise the issue in providing awareness regarding several risk factors associated with non-communicable diseases. As provided, hypertension has already affected 125 million of people specifically in the region of Eastern Mediterranean. Approximately, $97 \%$ of physicians agreed with idea of controlling the problem, by providing preventive measures and related problems that further complicate the problem (Wagialla \& Elnimeiri 2016). However, risk factors, such as; family history of hypertension, obesity, smoking, stress, diabetes etc. are some of the outlining problems discussed in the given framework of the study.

The significant of the study lies in the fact that it addresses the prevalence of hypertension and the risk factors associated in the districts of Al-Riyadh and Khartoum state of Sudan. The major concern of the problem is provided to people belonging to a middle-aged group. Other factors such as, stress, social status, Obesity and medical history of hypertension is given valuable importance. Besides this, findings provided by the given study are essential for future researchers and people undergoing through the given problem. Other than this, medical experts and health management team working in the above-mentioned areas can equally benefit from the results proposed by the study. Results proposed by the study can be generalized to other countries and districts up to certain extent. 


\section{Methods}

\subsection{Study Design}

The present study has applied a cross-sectional study design for evaluating the association between lifestyle and hypertension. It has used the quantitative approach for collecting, processing, and analyzing the data. The rationale behind the adoption of the particular design is based on its efficacy to produce authentic and effective results, which are easy to interpret by the reader.

\subsection{Study Population and Sample}

The participants for the study were residents of the Riyadh district in Khartoum, Sudan. Among the eight wards, the participants (male and female) were recruited using simple random sampling from ward number five. A total of 138 participants were included in the study. The sample size formula determined the size of the sample, i.e.,

$$
\text { Sample size }=\frac{Z^{2} *(p) *(1-p)}{C^{2}}
$$

\subsection{Ethical Concerns}

Initially, the researcher acquired approval from the Institutional Review Board for conducting the study. Also, the participants were communicated with the objective and scope of the study. The researcher also obtained verbal consent from the participants and also communicated about the confidentiality and anonymity of the collected data.

\subsection{Data Collection}

A close-ended questionnaire was used for conducting the survey. The questions of the questionnaire dealt with the information related to socio-demographic factors, hypertension risk factors, and arterial blood pressure measurement. Each item of the questionnaire was categorized for finding the relevant data. The validity and reliability of the questionnaire were assessed prior to its distribution, where three social science experts were contacted for its review. The changes were made based on the provided feedback of the experts. The reliability was ensured through Cronbach alpha value, i.e., which was found to be 0.87 , denoting high reliability. The questionnaire was distributed by attaining permission from the Nurse Director, where it was supplied to the participants, and a period of 3 weeks was provided for filling the questionnaire.

\subsection{Data Analysis}

The collected data was analyzed using Statistical Package for the Social Sciences (SPSS) version 20.0. Frequencies and percentages were calculated. The data was also computed for chi-square.

\section{Results}

The responses of the participants are statically studied to assess the association between healthy lifestyle and management of hypertension. Table 1 shows the prevalence of hypertension among the participants where $28 \%$ responded positively; whereas, $72 \%$ responded negatively.

Table 1. Prevalence of hypertension among adults in the Riyadh area in April 2015

\begin{tabular}{lcc}
\hline Variable & Frequency & Percentage \\
\hline Hypertension & & \\
\hline & Yes & $28 \%$ \\
\hline No & $72 \%$ \\
\hline
\end{tabular}

Table 2 depicts the association between the participant's age and hypertension. Based on the responses, it is found that majority of the participants were in the age bracket 15 to 30 years (73), followed by 31-45 years (29) as well as 46 to 60 years (25). Only a few participants (11) were aged between 61 to 75 years. It also shows that majority of the hypertension cases occurred among the age group 46 to 60 years (19). The chi-square value achieved is 0.001 which indicated a strong association between hypertension and age. The risk ratio computed for hypertension and age is found to be high i.e. 0.46. 
Table 2. Association between hypertension and age among adults at the Riyadh area in April 2015

\begin{tabular}{|c|c|c|c|c|c|c|}
\hline & & \multicolumn{3}{|c|}{ Hypertension } & \multirow[t]{2}{*}{ P-value } & \multirow[t]{2}{*}{ Risk Ratio } \\
\hline & & Yes & No & Total & & \\
\hline \multirow[t]{4}{*}{ Age } & $15-30$ & 3 & 70 & 73 & \multirow[t]{4}{*}{.001} & 1 (ref) \\
\hline & $31-45$ & 10 & 19 & 29 & & $0.46(0.42-0.47)$ \\
\hline & $46-60$ & 19 & 6 & 25 & & \\
\hline & $61-75$ & 7 & 4 & 11 & & \\
\hline Total & & 39 & 99 & 138 & & \\
\hline
\end{tabular}

Responses of the participants indicated that a significant portion of the sample were males (93) followed by females (45). The observed hypertension cases majorly occurred in males (25) as compared to females (14). The achieved p-value (0.296) denotes an insignificant association between hypertension and sex. The risk ratio computed for hypertension and sex is found to be low 0.92 .

Table 3. Association between Hypertension and Sex among adults at the Riyadh area in April 2015

\begin{tabular}{lccccc}
\hline & & Hypertension & \multicolumn{2}{c}{ P-value } & Risk Ratio \\
\cline { 2 - 4 } & Yes & No & Total & & \\
\hline Male & 25 & 68 & 93 & 0.296 & $0.92(0.87-1.00)$ \\
& & & & \\
Female & 14 & 31 & 45 & \\
Total & 39 & 99 & 138 & \\
\hline
\end{tabular}

The marital status was also analyzed for the participants (Table 4). The achieved responses indicated that much of the sample is single (75), followed by married (54), and divorced (4) as well as widows (5). Assessment of the hypertension showed that 27 married individuals among 54 mostly reported hypertension, as well as 4 widows among 5. The achieved p-value (0.001) reveals a significant association between hypertension and social status. The risk ration found for hypertension and social status is high, i.e., 0.44 .

Table 4. Association between hypertension and social status among adults at the Riyadh area in April 2015

\begin{tabular}{lllllll}
\hline \multirow{2}{*}{ Social status } & & \multicolumn{2}{l}{ Hypertension } & P-value & Risk Ratio \\
\cline { 3 - 4 } & Single & 6 & 69 & 75 & .001 & 1 (ref) \\
& Married & 27 & 27 & 54 & & $0.44(0.42-0.47)$ \\
& Divorced & 2 & 2 & 4 & & \\
\cline { 5 - 6 } Total & Widow & 4 & 1 & 5 & & \\
\hline
\end{tabular}

Table 5 indicated the education level as well as its association with hypertension. The collected data reveals that the most of the participants were graduates (89), following participants with secondary (19) and primary education (18). The majority of the reported cases of hypertension were observed for graduates (19). The p-value of the responses depicted an insignificant association between hypotension and level of education. The risk ratio computed is found to be low 0.87 . 
Table 5. Association between Hypertension and level of education among adults at the Riyadh area in April 2015

\begin{tabular}{|c|c|c|c|c|c|c|}
\hline & & \multicolumn{3}{|c|}{ Hypertension } & \multirow[t]{2}{*}{$\mathrm{P}$-value } & \multirow[t]{2}{*}{ Risk Ration } \\
\hline & & Yes & No & Total & & \\
\hline \multirow[t]{6}{*}{ Level of education } & Uneducated & 3 & 1 & 4 & & 1 (ref) \\
\hline & Khalwa & 1 & 2 & 3 & & $0.87(0.87-0.1)$ \\
\hline & Primary education & 9 & 9 & 18 & & \\
\hline & Secondary education & 5 & 14 & 19 & & \\
\hline & graduate & 19 & 70 & 89 & & \\
\hline & Post-graduate & 2 & 3 & 5 & & \\
\hline Total & & 39 & 99 & 138 & & \\
\hline
\end{tabular}

Table 6 shows the smoking tendency among the participants. It depicted that the majority of the participants were non-smokers (102), where the majority of them had no hypertension (73). The smoking participants were 36 where 26 had no hypertension while 10 reported hypertension. The achieved p-value revealed no association between hypertension and smoking $(0.832)$. The risk ratio computed is found to be low 0.84 .

Table 6. Association between Hypertension and Smoking among adults at the Riyadh area in April 2015

\begin{tabular}{|c|c|c|c|c|c|c|c|}
\hline & & & \multicolumn{3}{|c|}{ Hypertension } & \multirow[t]{2}{*}{ P-Value } & \multirow[t]{2}{*}{ Risk Ratio } \\
\hline & & & Yes & No & Total & & \\
\hline Do & you & Yes & 10 & 26 & 36 & .832 & 1 (ref) \\
\hline Smoke? & & No & 29 & 73 & 102 & & $0.84(0.87-0.1)$ \\
\hline Total & & & 39 & 99 & 138 & & \\
\hline
\end{tabular}

The exercise prospects among the participants are shown in Table 7. It indicated that 96 participants did not indulge in exercise; whereas, 35 of the participants did exercise. The cases of hypertension showed that 33 non-exercising participants had hypertension whereas it was also found for seven exercising participants. The $\mathrm{p}$-value of the responses depicted an insignificant association between hypotension and exercise (.100). Similar is the finding concerning the risk ratio, which is 0.87 .

Table 7. Association between hypertension and exercise among adults at the Riyadh area in April 2015

\begin{tabular}{|c|c|c|c|c|c|c|}
\hline & & \multicolumn{3}{|c|}{ Hypertension } & \multirow[t]{2}{*}{ P-value } & \multirow[t]{2}{*}{ Risk Ratio } \\
\hline & & Yes & No & Total & & \\
\hline \multirow{2}{*}{$\begin{array}{l}\text { Do you perform the } \\
\text { exercise? }\end{array}$} & Yes & 7 & 35 & 42 & .100 & 1 (ref) \\
\hline & No & 33 & 63 & 96 & & $0.87(0.87-0.1)$ \\
\hline Total & & 40 & 98 & 138 & & \\
\hline
\end{tabular}

Table 8 shows the association of stress and hypertension among the participants, where 84 reported stress while 54 did not. Among the reporting participants, 9 had hypertension whereas the number was 31 for the non-stressful participants. A strong association is revealed by the achieved p-value, i.e., 0.10.

Table 8. Association between Hypertension and Stress among adults at the Riyadh area in April 2015

\begin{tabular}{lcccccc}
\hline & & \multicolumn{3}{c}{ Hypertension } & \multirow{2}{*}{ P-value } & Risk Ratio \\
\cline { 3 - 5 } & & Yes & No & Total & \\
\hline Do you deal with stress & Yes & 9 & 45 & 54 & .010 & 1 (ref) $0.67(0.60-0.72)$ \\
& No & 31 & 53 & 84 & \\
Total & & 39 & 99 & 138 & \\
\hline
\end{tabular}


The cases of diabetes among the participants are shown in Table 9. It illustrates that 113 had no diabetes whereas $25 \mathrm{did}$. Among the 113 non-diabetic participants, 12 had hypertension, whereas, among 25 diabetic participants, 12 had hypertension. The achieved p-value indicated a strong association of hypertension and diabetes (0.050). The risk ratio is found to be low (0.95).

Table 9. Association between hypertension and diabetes among adults at the Riyadh area in April 2015

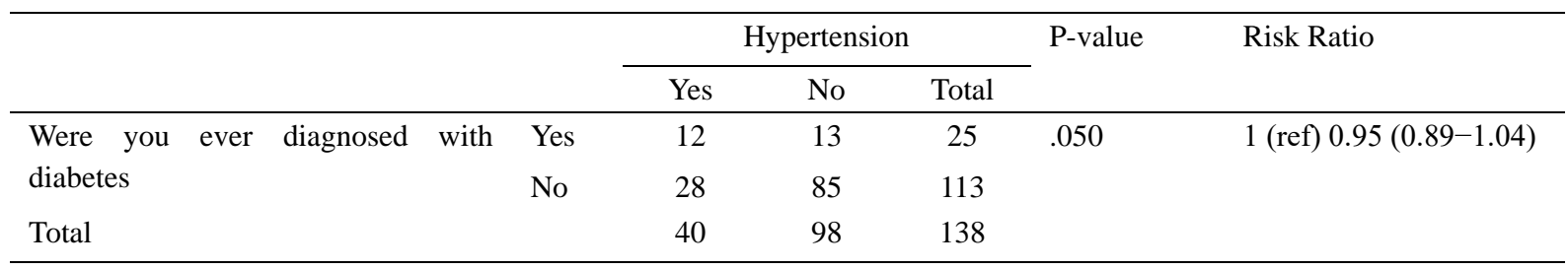

Table 10 shows the carbohydrate food consumption among the participants. It demonstrated that 98 participants consumed carbohydrate food while 40 did not. Among the 98 carbohydrate consuming participants, 34 had hypertension, whereas, among 40 non-carbohydrate consuming, 6 had hypertension. The achieved p-value (0.065) shows a significant association between hypertension and diabetes. The risk ratio between hypertension and carbohydrate food is found to be low (0.96).

Table 10. Association between hypertension and carbohydrate food among adults at the Riyadh area in April 2015

\begin{tabular}{lcccccc}
\hline & & \multicolumn{3}{c}{ Hypertension } & P-value & \multirow{2}{*}{ Risk Ratio } \\
\cline { 3 - 5 } & & Yes & No & Total & & \\
\hline Is your diet rich in & Yes & 34 & 64 & 98 & .065 & 1 (ref) \\
carbohydrates & No & 6 & 34 & 40 & & $0.96(0.90-1.04)$ \\
Total & & 40 & 98 & 138 & & \\
\hline
\end{tabular}

The fruit-eating habit of the participants is shown in Table 11. It revealed that banana was the most consumed food among the participants, followed by peach (1) while 32 did not. The major cases of hypertension showed that 28 participants consumed banana while 9 consumed no food. The p-value (.957) depicted an insignificant association between hypotension and fruit eating. The risk ratio between hypertension and fruit-eating is found to be low (0.95).

Table 11. Association between hypertension and fruit-eating among adults at the Riyadh area in April 2015

\begin{tabular}{|c|c|c|c|c|c|c|}
\hline & & \multicolumn{3}{|c|}{ Hypertension } & \multirow[t]{2}{*}{ P-value } & \multirow[t]{2}{*}{ Risk Ratio } \\
\hline & & Yes & No & Total & & \\
\hline \multirow{4}{*}{$\begin{array}{l}\text { Do you take any of } \\
\text { these fruits in your diet }\end{array}$} & Banana & 28 & 69 & 98 & \multirow[t]{4}{*}{.957} & \multirow[t]{4}{*}{1 (ref) $0.95(0.89-1.04)$} \\
\hline & Peach & 1 & 6 & 7 & & \\
\hline & Cranberry & 0 & 1 & 1 & & \\
\hline & None & 9 & 23 & 32 & & \\
\hline \multicolumn{2}{|l|}{ Total } & 38 & 99 & 138 & & \\
\hline
\end{tabular}

\section{Discussion}

The prevalence of hypertension is observed to be high among the residents of the developing countries, which continues to rise at an alarming rate. Consequently, the study was focused on assessing the cases of hypertension in the developing country, Sudan. The results of the study showed that hypertension prevalence is low in the country. The low prevalence of hypertension is also reported in Turkey when Dogan, Toprak, and Demir (2012) analyzed its prevalence statistics. It also stated that prevalence of hypertension is also dependent upon other risk factors inclusive of gender, age, hypertension family history, income levels, diabetes mellitus, body mass index (BMI), and Chronic heart disease (CHD). Contrary to it, the study by Mbah, Eme, and Ezeji (2013) on the Nigerian population showed a slightly higher prevalence of hypertension. It may be due to the inclusion of 
higher other risk factors which were not accounted in the present study, i.e. consumption of alcoholic beverages and obesity.

Assessment of the hypertension cases in the context of the age revealed that high age leads to increase episodes of hypertension among the Sudanese population. Yang et al. (2017) also found similar results on the Korean population highlighting that higher age leads to increased prevalence of hypertension in the world. However, Bruno et al. (2016) reported contrary results as it found the most prevalence of hypertension cases in the young adults. This may be due to the difference in the population characteirstics and region.

The gender assessment in the present study revealed that gender impacts the hypertension cases. It reported that increased hypertension cases among males. Babiker, Elkhalifa, and Moukhyer (2013) earlier study in Sudan also supplements these findings. These results were derived by studying 200 participants (male and female) where (61\%) hypertensive participants were males as compared to females (15\%). This highlights the prevalence of the stagnant prevalence of hypertension in Sudan. Another study of Bani (2011) on the Saudi population showed that strong hypertension correlation with the male gender.

The present study noted that social status impacted the occurrence of hypertension among the population of East Sudan. These are corroborated by the findings of Gupta et al. (2017) which established that social status impacts hypertension prevalence in the region. The impact of stress on the occurrence of hypertension is reported by Kucukler et al. (2011), similar to the present study findings. Similarly, Belkar et al. (2018) highlighted that stress induces hypertension. He also stated various factors accounts to its prevalence such as job strain, social environment, race, and emotional distress.

The findings of the study are found limiting such as the study examined only a small number of participants; the inclusion of more participants can further strengthen the results. Accordingly, a quantitative approach was used, whereas, adopting a qualitative approach can also prove to be beneficial for the study. The study suggests conducting an interview with the health care professionals related to the lifestyle and hypertension can provide valuable insights. Also, the generalizability of the study is limited due to its restriction to a particular population. Therefore, study directs the future researches to explore the same objective in other regions and also including factors which were not accounted in the present study such as individual's motivation, cultural dietary habits, and access to sources of healthy food as well as resources and opportunities related to physical activity. The inclusion of the elderly population can also help to reveal new insights on the research subject. Similarly, the alcohol consumption can also be incorporated which is likely to impact the study results.

\section{Conclusion}

The study concludes that healthy lifestyle can help reduce the hypertension prevalence, which helps an individual in controlling his health. The findings conclude that the lifestyle of the individuals gets impacted by the cultural infrastructure, socioeconomic conditions, social relationships, and their personality. In order to overcome or mitigate the prevalence of hypertension, the study suggests instigation of the educational programs which promote healthy lifestyle practices among the population. Further, it suggests screening of the population for the hypertension disease and provisioning of the preventive methods and its information should be practiced on a regular basis. It also suggests that regulatory authorities must focus on improving the educational avenues which assist in the adoption of healthy lifestyles and behaviors along with behavioral habits at a younger age. The focus on the younger age is due to the fact that habit accustomed from childhood remain ingrained to adulthood.

\section{Acknowledgements}

The authors are very thankful to all the associated personnel in any reference that contributed in/for the purpose of this research. Further, this research is not funded through any source.

\section{References}

Aldiab, A., Shubair, M. M., Al-Zahrani, J. M., Aldossari, K. K., Al-Ghamdi, S., Househ, M., ... \& Jradi, H. (2018). Prevalence of hypertension and prehypertension and its associated cardioembolic risk factors; A population based cross-sectional study in Alkharj, Saudi Arabia. BMC Public Health, 18(1), 1327. https://doi.org/10.1186/s12889-018-6216-9

Alharbi, S. A., Wedhaya, M. A., Alluqmani, M. F., \& Alrehaili, S. S. (2017). Evaluation of Knowledge in Hypertensive Saudi Population in Makkah, KSA. Egyptian Journal of Hospital Medicine, 67(2). https://doi.org/10.12816/0037834

Alkahtani, S. A., \& Al-Hariri, M. T. (2016). Hypertension and employee's health: A cross-sectional analysis in 
private sector at Eastern province, Saudi Arabia. Hypertension, 5(2), 61-66. https://doi.org/10.4103/2278-0521.192999

Babiker, F. A., Elkhalifa, L. A., \& Moukhyer, M. E. (2013). Awareness of hypertension and factors associated with uncontrolled hypertension in Sudanese adults : cardiovascular topic. Cardiovascular Journal of Africa, 24(6), 208-212. https://doi.org/10.5830/cvja-2013-035

Baig, M., Gazzaz, Z. J., Gari, M. A., Al-Attallah, H. G., Al-Jedaani, K. S., Mesawa, A. T., \& Al-Hazmi, A. A. (2015). Prevalence of obesity and hypertension among University students' and their knowledge and attitude towards risk factors of Cardiovascular Disease (CVD) in Jeddah, Saudi Arabia. Pakistan Journal of Medical Sciences, 31(4), 816.

Bani, I. A. (2011). Prevalence and related risk factors of Essential Hypertension in Jazan region, Saudi Arabia. Sudanese J Public Health, 6, 45-50.

Bhelkar, S., Deshpande, S., Mankar, S., \& Hiwarkar, P. (2018). Association between Stress and Hypertension among Adults More Than 30 Years: A Case-Control Study. National Journal of Community Medicine, 9(6), 430-433.

Booth III, J. N., Li, J., Zhang, L., Chen, L., Muntners, P., \& Egan, B. (2017). Trends in prehypertension and hypertension risk factors in US adults: 1999-2012. Hypertension, 70(2), $275-284$. https://doi.org/10.1161/hypertensionaha.116.09004

Bruno, R. M., Pucci, G., Rosticci, M., Guarino, L., Guglielmo, C., Rosei, C. A., \& Fedecostante, M. (2016). Association between lifestyle and systemic arterial hypertension in young adults: a national, survey-based, cross-sectional study. High Blood Pressure \& Cardiovascular Prevention, 23(1), 31-40. https://doi.org/10.1007/s40292-016-0135-6

Bui Van, N., Pham Van, Q., Vo Hoang, L., Bui Van, T., Nguyen Hoang, N., Do Nam, K., \& Chu, D. T. (2018). Prevalence and risk factors of hypertension in two communes in the Vietnam Northern Mountainous, 2017. BioMed Research International, 2018. https://doi.org/10.1155/2018/7814195

De Boer, I. H., Bangalore, S., Benetos, A., Davis, A. M., Michos, E. D., Muntner, P., ... \& Bakris, G. (2017). Diabetes and hypertension: a position statement by the American Diabetes Association. Diabetes Care, 40(9), 1273-1284.

Dogan, N., Toprak, D., \& Demir, S. (2012). Hypertension prevalence and risk factors among adult population in Afyonkarahisar region: a cross-sectional research. Anadolu Kardiyoloji Dergisi/the Anatolian Journal of Cardiology. https://doi.org/10.5152/akd.2012.009

Forouzanfar, M. H., Liu, P., Roth, G. A., Ng, M., Biryukov, S., Marczak, L., ... \& Ali, R. (2017). Global burden of hypertension and systolic blood pressure of at least 110 to $115 \mathrm{~mm} \mathrm{Hg}, 1990-2015$. Jama, 317(2), 165-182. https://doi.org/10.1001/jama.2016.19043

Gupta, R., Kaur, M., Islam, S., Mohan, V., Mony, P., Kumar, R., \& Antony, J. (2017). Association of household wealth index, educational status, and social capital with hypertension awareness, treatment, and control in South Asia. American Journal of Hypertension, 30(4), 373-381. https://doi.org/10.1093/ajh/hpw169

Gutierrez, J., Alloubani, A., Mari, M., \& Alzaatreh, M. (2018). Cardiovascular disease risk factors: Hypertension, diabetes mellitus and obesity among Tabuk Citizens in Saudi Arabia. The Open Cardiovascular Medicine Journal, 12, 41. https://doi.org/10.2174/1874192401812010041

Hosseinpanah, F., Mirbolouk, M., Mossadeghkhah, A., Barzin, M., Serahati, S., Delshad, H., \& Azizi, F. (2016). Incidence and potential risk factors of obesity among Tehranian adults. Preventive Medicine, 82, 99-104. https://doi.org/10.1016/j.ypmed.2015.11.015

Kucukler, N., Yalçin, F., Abraham, T. P., \& Garcia, M. J. (2011). Stress induced hypertensive response: should it be evaluated more carefully?. Cardiovascular Ultrasound, 9(1), 22. https://doi.org/10.1186/1476-7120-9-22

Masoodi, Z. A., \& Riyaz, A. M. (2016). Prevalence and determinants of hypertension in Kashmir: A cross sectional study. IOSR J Dent Med Sci, 15(6), 57-64.

Mbah, B. O., Eme, P. E., \& Ezeji, J. (2013). Prevalence and risk factors of hypertension among middle-aged adults in Ahiazu Mbaise Local Government Area, Imo State, Nigeria. International Journal of Basic \& Applied Sciences, 13, 26-30.

Mills, K. T., Bundy, J. D., Kelly, T. N., Reed, J. E., Kearney, P. M., Reynolds, K., ... \& He, J. (2016). Global 
disparities of hypertension prevalence and control: a systematic analysis of population-based studies from 90 countries. Circulation, 134(6), 441-450. https://doi.org/10.1161/circulationaha.115.018912

Mozaffarian, D., Benjamin, E. J., Go, A. S., Arnett, D. K., Blaha, M. J., Cushman, M., ... \& Huffman, M. D. (2015). Executive summary: heart disease and stroke statistics - 2015 update: A report from the American Heart Association. Circulation, 131(4), 434-441. Doi: https://doi.org/10.1161/cir.0000000000000157

Najimi, A., Mostafavi, F., Sharifirad, G., \& Golshiri, P. (2016). Patient's Beliefs about Adherence to Medication toward Hypertension: a Qualitative Study. International Journal of Advanced Biotechnology and Research, 7, 1555-1561.

Naser, N., Dzubur, A., Durak, A., Kulic, M., \& Naser, N. (2016). Blood pressure control in hypertensive patients, cardiovascular risk profile and the prevalence of masked uncontrolled hypertension (MUCH). Medical Archives, 70(4), 274. https://doi.org/10.5455/medarh.2016.70.274-279

Osman, S., Costanian, C., Annan, N. B., Fouad, F. M., Jaffa, M., \& Sibai, A. M. (2019). Urbanization and Socioeconomic Disparities in Hypertension among Older Adult Women in Sudan. Annals of Global Health, 85(1). Doi: https://doi.org/10.5334/aogh.2404

Saeed, A. A. W. (2017). Combined Systolic Diastolic Hypertension among Adults in Saudi Arabia: Prevalence, Risk Factors and Predictors: Results of a National Survey. International Journal of Medical Research \& Health Sciences, 6(6), 171-176.

Saeed, A. A., \& Al-Hamdan, N. A. (2016). Isolated Diastolic Hypertension among Adults in Saudi Arabia: Prevalence, Risk Factors, Predictors and Treatment. Results of a National Survey. Balkan Medical Journal, 33(1), 52. https://doi.org/10.5152/balkanmedj.2015.153022

Saeedi, M. Y., Alsafi, Y. H., Afghan, S. Z., Al-Khudair, S. S., Al-Dhwailea, S. K., \& Badawi, A. A. (2018). Cardiovascular risk assessment in general population at primary health care centers in Saudi Arabia: Using the World Health Organization/International Society of Hypertension risk prediction charts. International Society of Hypertension Risk Prediction Charts.

Sokrab, T. E. O., Sid-Ahmed, F. M., \& Idris, M. N. (2002). Acute stroke type, risk factors, and early outcome in a developing country: A view from Sudan using a hospital-based sample. Journal of Stroke and Cerebrovascular Diseases, 11(2), 63-65. https://doi.org/10.1053/jscd.2002.126690

Ss, M. A. (2016). A review of prevalence of obesity in Saudi Arabia. J Obes Eat Disord, 2(2). https://doi.org/10.21767/2471-8203.100025

Suliman, A. (2011). The state of heart disease in Sudan. Cardiovascular Journal of Africa, 22(4), 191. https://doi.org/10.5830/cvja-2010-054

Van Gaal, L. F., Mertens, I. L., \& Christophe, E. (2006). Mechanisms linking obesity with cardiovascular disease. Nature, 444(7121), 875.

Veiga Jardim, T., Lima Sousa, A. L., Rolim Povoa, T. I., Sebba Barroso, W. K., Chinem, B., Jardim, L., ... \& Veiga Jardim, P. C. B. (2015). The natural history of cardiovascular risk factors in health professionals: 20-year follow-up. BMC Public Health, 15, 1111. https://doi.org/10.1186/s12889-015-2477-8

Wagialla, N. A., \& Elnimeiri, M. K. M. (2016). Management of Hypertension by Primary Health Care Providers in Khartoum, Sudan. Public Health Open J., 1(3), 66-70. https://doi.org/10.17140/phoj-1-113

World Health Organization. (2015). Health Profile 2015, Sudan. Retrieved from http://applications.emro.who.int/dsaf/EMROPUB_2017_EN_19610.pdf

Yang, M. H., Kang, S. Y., Lee, J. A., Kim, Y. S., Sung, E. J., Lee, K. Y., ... \& Lee, S. Y. (2017). The effect of lifestyle changes on blood pressure control among hypertensive patients. Korean Journal of Family Medicine, 38(4), 173. https://doi.org/10.4082/kjfm.2017.38.4.173

\section{Copyrights}

Copyright for this article is retained by the author(s), with first publication rights granted to the journal.

This is an open-access article distributed under the terms and conditions of the Creative Commons Attribution license (http://creativecommons.org/licenses/by/4.0/). 